\title{
Ranking of the Determinants Affecting Students' Attitude of a Higher Education Institution: Application of AHP
}

\author{
Shahriyar Anam \\ Department of Business Administration, University of Asia Pacific \\ Dhaka, Bangladesh \\ Mahbubul Haque (Corresponding author) \\ Department of Business Administration, University of Asia Pacific \\ Dhaka, Bangladesh
}

E-mail: mahbubuap@yahoo.com

Sarwar R. Chowdhury

Department of Business Administration, University of Asia Pacific

Dhaka, Bangladesh

Doi:10.5296/ ijhrs.v5i2.6040 URL: http://dx.doi.org/10.5296/ ijhrs.v5i2.6040

\begin{abstract}
With the higher education landscape getting increasingly competitive, the role of marketing has come to the surface. The current study is conducted to prioritise the determinants affecting the attitude of the students pursuing their studies in a particular business school at a private university of Bangladesh. Five criteria are considered in this regard where Analytic Hierarchy Process (AHP) is applied to rank the chosen criteria. The results derived through Expert Choice software version 11.0 indicate that promotional activities are ranked first having a weight of about $52 \%$; this is followed by the quality of teaching staff with around $22 \%$. The other two criteria 'Service provided by the business school' and 'Campus facilities' are ranked third and fourth with about $12 \%$ and $11 \%$, respectively. Co-curricular activities turn out to be of least importance having a weight of $3.4 \%$ only. Based on the results, a few marketing strategies are recommended for the policy makers to consider as they cope with the pressure of heightened competition in the market. Suggestions for some avenues of future research are also put forward.
\end{abstract}

Keywords: Student Selection Criteria, Analytic Hierarchy Process, Private University, Marketing Strategy 


\section{Introduction}

The higher-education landscape continues to evolve at a rapid pace where the institutions are under growing pressure to cater to the needs of the students. With the environment getting increasingly competitive, the role of marketing has come to the surface. In this regard, an important aspect worth considering, according to Gunawardana (2013), would be to figure out student attitude in selecting their preferred university. Such an understanding of prospective students' choice process has high potential for developing university marketing strategies (Kusumawati, 2013).

Since the Private University Act 1992, Bangladesh has witnessed a steadily increasing number of private universities offering education to the students. The fast growing number of higher-education institutions (HEI) in Bangladesh has been putting increasing pressure on the institutions to be fiercely competitive (Ashraf et al., 2009). The competition is not only about offering high-quality education, or about hiring faculty with impressive credentials, rather the service/s offered by the institutions, and the branding of the image of the institution are going to be integral parts of students' choice criteria for selecting a HEI. Thus, it is of high significance to gauge the perception of the potential students regarding the products and services offered by the universities (Blumenstyk, 2008).

A reputed private university of Bangladesh, the focal point of this study, has been offering courses/programs under different departments. The different programs have different priorities as the competitions faced by different programs are diverse in nature. While a particular program is facing competition from 8 to 9 institutions, another is competing with about $70+$ institutions. While in case of one program accreditation from a particular institution is extremely important, for another the attractiveness of the campus and its location are the major elements for consideration of marketing strategy.

Since the business school of this particular private university is currently facing the fiercest competition among the different programs offered by the institution, the main objective of the study is to analyze the priorities of the targeted customers/students in this particular area which would help the institution focus on the most significant aspects for formulating the required marketing strategy. Specifically, this study seeks to prioritise the important determinants that influence the attitude of the students regarding their preferred choice of a particular university. In doing so, it seeks to gain an insight into the appropriate marketing strategies required by the particular business school as it navigates an intensely competitive landscape of higher education in private universities in Bangladesh.

The paper is structured as follows: next chapter sheds light on the various studies performed vis-a-vis students' perception on the relevant criteria affecting their attitude and selection of higher educational institutions in different context. This is followed by a discussion on the methodology, i.e., AHP, employed in this study. Next, findings generated through Expert Choice software on the rankings of the criteria are illustrated. The implications and marketing strategies required to be considered by the authorities are then discusses. The paper concludes summarising the objectives and the findings, as well as offering some suggestions for avenues of possible future research in this regard. 


\section{Literature Review}

There are a large number of studies done in ascertaining the selection criteria preferred by the students in choosing higher educational institutions. A brief discussion of the literature review relating to this aspect is presented below.

Gunawardana (2013) conducts a study in Sri Lanka on the choice criteria of potential students in selecting a university. The findings reveal that the major factors influencing student perception in this regard are facilities provided, duration and cost the degree and the teaching quality. The author observes that in this competitive era, the role of marketing has grown significantly and the university administrators must take it in due consideration.

This view is echoed by Kusumawati (2013) who performs a study on the determinants of selecting a higher education institution by the students in Indonesia. The study uses a mixed-methods approach and finds that recommendations from their families and friends, reputation, campus environment, location and cost of the program are the important criteria for the students to select a university in Indonesian context. The author also argues that stronger marketing efforts are needed on the part of the universities with a focus on institutional development, particularly in student recruitment process.

A study by Shah et al. (2013) on factors influencing student choice to study at private higher education institutions collected data from five different private HEI in Australia. Surveyed on 120 students undertaking higher education courses in different areas at different stages of their study, the selection of the participants was based on a number of student attributes, such as, gender, domestic/international, and their areas of discipline. The six factors influencing the students' choice to study at HEI were identified as: student perception, access and opportunity, learning environments, quality of teachers, course design, and graduate success. This study reinforces that student perception of the private HEI is an important determinant in influencing student choice to study at a particular institution.

Wiese et al. (2010) carry out a study surveying 1241 respondents from six South African Universities for identifying choice factors considered by students in selecting a HEI. The study aimed to identify factors to attract the right calibre students, to create unique position, to segment the student market more appropriately and to gain competitive advantage. The study identified quality of teaching as the most important choice factor. The choices also varied among different language and gender groups with multiculturalism scoring a high point among the respondents.

Shammot (2011) surveys fifty Jordanian students - twenty five male and twenty five female to ascertain the factors affecting their decision in selecting private universities. The study finds that while the male students consider the financial cost as the most significant determinant decision, the female cohorts regard word of mouth and university branding as the key elements in selecting their preferred universities.

A study conducted by Ashleigh and Janell (2010) on the influence of communication sources on a student's evaluation of university selection shows that students consult various communication sources including traditional, word of mouth and electronic word of mouth. 
In addition to these, trustworthiness, relevance, risks and expertise contributes in evaluation of the communication sources to allow for better understanding of their influence. The findings of the study shows that traditional and word of mouth are the dominant sources consulted.

Beswick (1989) performs a questionnaire survey on two hundred twenty seven first year students in Alberta, Canada to identify factors students consider in the university selection process. The principal finding of this study is that parents, particularly mothers, wield greater influence to affect the process. Besides, other factors, such as, the name of the institution, reputation of the program, course offerings, and proximity to home appear to be important in their decision-making process.

Ashraf et al. (2009) conduct a study on the students of about ten private universities in Bangladesh about the quality and cost of education. The results of the study indicate that factors, such as, faculty credentials, academic calendar, campus and research facility and tuition fees are important considerations, and the respondents believe that private universities in general provide better education but the tuition fees charged by them are very high.

Jamil et al. (2012) carry out a study on the students' selection criteria in choosing a private university in Bangladesh. Through a convenience sampling technique, the authors survey 100 students of ten private universities. The results of the study indicate that the quality of education offered by the university appears to be the prime criteria followed the tuition fees and non-involvement of the students in the politics. In this study, the authors also shed light on the respondents' socio-cultural background which would help the policy makers to formulate strategies to more effectively cater to the needs of the prospective students.

Thus, while there are studies done concerning student selection criteria as presented in the review presented above, there is a dearth of studies where the criteria are ranked, particularly by employing Analytic Hierarchy Process (AHP), the widely used framework in decision-making. The current study is an attempt in this regard, and is, therefore, expected to add to the extant body of literature vis-a-vis this issue of high concern for university policy makers.

\section{Methodology}

The present study applies analytic hierarchy process (AHP) as the method to find out the ranking of the criteria concerned with the students' attitude in their selection of a business school at a private university. A description of the AHP method highlighting the steps and the scale used in the process is provided below.

AHP is a multi-criteria decision-making approach that allows decision makers to quantify their subjective preferences of selection criteria, and then synthesize them across diverse criteria (Vaidya and Kumar, 2006). It is a widely used technique used to consider subjective decision making attributes and divides a complex decision problem into a hierarchical system of decision elements (Saaty, 1980). The three-step procedure for the AHP can be summarized as follows: 


\section{Macrothink}

- Constructing the hierarchical system: The AHP, in general, divides a complex problem into three levels of hierarchy: the overall goal of the problem; the evaluation criteria used; and the decision alternatives considered. In the current study, however, there are two levels shown as e.g. Figure 1, as it is aimed only at finding out the ranking of the criteria influencing the students' attitude vis-a-vis the particular business school.

- Making pair-wise comparisons for the criteria and for the decision alternatives: Second, pair-wise comparison matrices are constructed for all the criteria and the alternatives using a 9-point scale as e.g. Table 1, as suggested by Satty (1980). From the above matrices, weights of the criteria and the local weights of the alternatives are determined through normalization procedure.

- Calculating the weights and testing the consistency: Finally, the global weights of the alternatives are calculated by synthesis, i.e., by multiplying the local weights of each alternative with the priority of the same criterion and then adding them for all the criteria.

In order to test the consistency of the subjective preferences, the consistency ratio (C. R.) is measured, the threshold value of which is less than 0.10 . Values of the C.R. greater than 0.10 would point to the presence of serious inconsistencies in the decision-making process.

In this study, the criteria considered to be influencing students' attitude regarding the particular business school are: Campus facilities, Promotional activities, Quality of teaching staff, Service, and Curricular activities. This is presented in Figure 1.

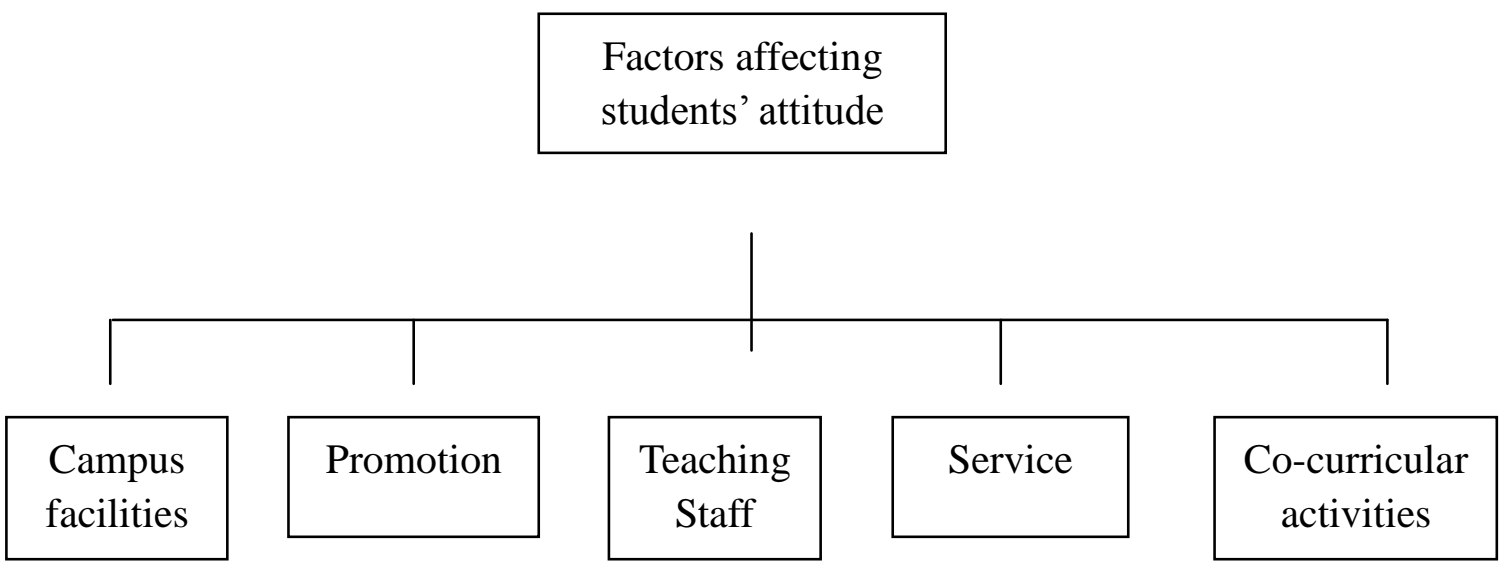

Figure 1: AHP Hierarchy Process in Students' Attitude 
Table 1: Fundamental scale for pair-wise comparisons

\begin{tabular}{|l|l|}
\hline Verbal Judgments of Preferences & Numerical Values \\
\hline Equally important & 1 \\
\hline Moderately more important & 3 \\
\hline Strongly more important & 5 \\
\hline Very strongly more important & 7 \\
\hline Extremely more important & 9 \\
\hline Intermediate values reflecting compromise & $2,4,6,8$ \\
\hline
\end{tabular}

\subsection{Data Collection and Data Analysis}

The AHP questionnaire is prepared with the five criteria that affect the attitude of the students studying at a particular business school. This questionnaire was delivered to a group of undergraduate students currently enrolled in the business school of that particular university. The questionnaire was filled out using the pair-wise comparison scale as shown as e.g. Table 1. Table 2 presents a filled out questionnaire. Expert Choice software is employed to find out the weights of the criteria affecting the students' attitude.

Table 2. Pair-wise comparison matrix for the criteria affecting students' attitude

\begin{tabular}{|l|l|l|l|l|l|}
\hline Matrix & $\begin{array}{l}\text { Campus } \\
\text { Facilities }\end{array}$ & Promotion & $\begin{array}{l}\text { Teaching } \\
\text { Staff }\end{array}$ & Service & $\begin{array}{l}\text { Co-curricular } \\
\text { Activities }\end{array}$ \\
\hline $\begin{array}{l}\text { Campus } \\
\text { Facilities }\end{array}$ & 1 & $1 / 5$ & $1 / 3$ & 1 & 5 \\
\hline Promotion & 1 & 5 & 3 & 3 & 9 \\
\hline $\begin{array}{l}\text { Teaching } \\
\text { Staff }\end{array}$ & & 1 & 1 & 1 & 5 \\
\hline Service & & & & & 1 \\
\hline $\begin{array}{l}\text { Co-curricular } \\
\text { Activities }\end{array}$ & & & & & \\
\hline
\end{tabular}




\section{Findings of the Study}

As generated through Expert Choice software version 11 and shown as e.g. Figure 2, the criterion, 'promotional activities' assumes an overwhelming importance (above 52\%) for the students of the business school at the particular private university. This is followed by the qualified teaching staff with around $22 \%$. Service provided and campus facilities catering to the needs of the students are ranked next with about $12 \%$ and $11 \%$, respectively. The criterion of co-curricular activities turns out to be of much lesser importance with about $3 \%$ only. The result is judged satisfactory as the inconsistency in the judgments is found out to be $8 \%$, which is below the threshold value of $10 \%$.

\section{Model Name: Criteria Affecting Students'Attitude}

\section{Priorities with respect to: \\ Goal: Ranking of the Criteria}

\section{Campus Facilities \\ Promotion \\ Teaching Staff \\ Service \\ Cocurricular Activities \\ Inconsistency $=\mathbf{0 . 0 8}$ with 0 missing .judgments.}

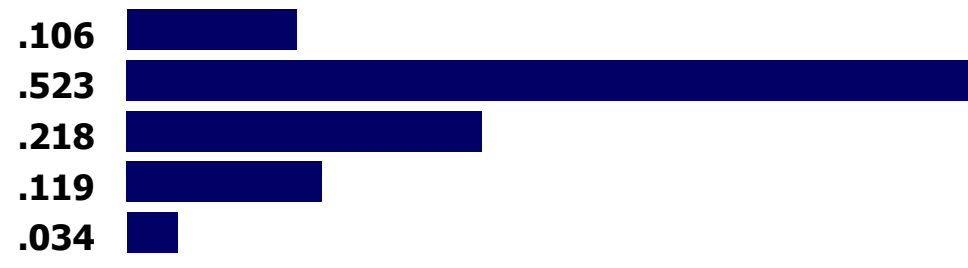

Figure 2: Rankings of the Criteria Affecting Students' Attitudes

\section{Conclusions, Implications and Suggestions for Future Research}

The current study is conducted to prioritise the determinants affecting the attitude of the students as they consider pursuing their studies in higher education institutions, in this case, a business school at a private university of Bangladesh. Five criteria are considered in this regard. Analytic Hierarchy Process (AHP), the widely used framework in decision-making process, is applied. Expert Choice software version 11.0 is used. The results indicate that promotional activities are ranked first having a weight of about 52\%; this is followed by the quality of teaching staff with around $22 \%$. Service provided by the business school and campus facilities are ranked third and fourth with about $12 \%$ and $11 \%$, respectively. Co-curricular activities turn out to be of least importance having a weight of $3.4 \%$ only.

The results have important implications for the concerned business school or the university policy makers at large. As the business schools are locked in a cut-throat competition with one another, vying for large number of student enrolments every semester, promotion holds the key to its success. This should be a prime marketing strategy and can be done through 
extensive media coverage, highlighting its strength of qualified faculty staff, robust infrastructural facilities, various programs taken up toward building a good rapport between the school and the industry, etc. The importance of qualified faculty staff is another factor that, as the results indicate, needs to be seriously looked into. In this era of knowledge economy, having a faculty staff equipped with the latest research findings in their own areas is an absolute imperative. Thus, policy makers keep it in mind to select experienced faculties with strong academic and research backgrounds. The other factors, service provided by the authority and campus facilities, come in third and fourth in ranking, as these also seriously affect students' satisfaction toward a particular business school. Along with the co-curricular activities, all these factors call for urgent considerations by the concerned business school authority as it navigates a stiff competitive landscape in the times ahead.

While the current study offers an insight into the importance of various determinants affecting the students' attitude as they continue their academic pursuit in the said sbusiness school, it has some limitations as well. These are stated below:

- The factors considered in this study are only five. Others, such as location, can be of high importance for prospective students. Any future study, therefore, needs to consider these for getting a better picture in this regard.

- AHP is used as the research methodology. However, no sub-criteria or the alternatives are considered in this study. This is another potential area that might be considered in any future work.

\section{References}

Ashleigh, B, \& Janelle, R. (2010). The influence of communication sources on a student's evaluation of university selection: a regional university study. In Australian and New Zealand Marketing Academy Conference: doing more with less, 1-10, 29 November - 1 December 2010, Christchurch, New Zealand.

Ashraf, M. A., Ibrahim, Y., \& Joarder, M. H. R. (2009). Quality education management at private universities in Bangladesh. Jurnal Pendidik dan Pendidikan, 24, 17-32.

Beswick, R. L. K. (1989). A study of factors associated with student choice in the university selection process. A Thesis in Master of Education, The University of Lethbridge, Lethbridge, Alberta, Canada.

Blumenstyk, G. (2008). Good research and faculty buy-In: two keys to effective marketing. Chronicle of Higher Education, 54(33), A21.

Gunawardana, K. D. (2013). An empirical study on students' perceptions of choice criteria in the selection of degree awarding institutes with foreign affiliations in Sri Lanka. Working Paper Series (April), accessed on July 21, 2014, available at SSRN: http://papers.ssrn.com/sol3/papers.cfm?abstract_id=2250572

Jamil, M. A. A., Sarker, M. M., \& Abdullah, M. (2012). Students' choice criteria to select a 


\section{Macrothink}

International Journal of Human Resource Studies

ISSN 2162-3058 2015, Vol. 5, No. 2

private university for their higher education in Bangladesh. European Journal of Business and Management, 4(17), 177-185.

Kusumawati, A. (2013). Students' perceptions of choice criteria in the selection of an Indonesian public university, Doctor of Business Administration thesis, Sydney Business School, University of Wollongong, accessed on July 21, 2014, available at http://ro.uow.edu.au/theses/3933

Saaty, T. L. (1980). The Analytic Hierarchy Process: Planning, Priority Setting, Resource Allocation. New York: McGraw-Hill.

Shah, M., Nair, C. S., \& Bennett, L. (2013.) Factors influencing student choice to study at private higher education institutions. Quality Assurance in Education, 21(4), 402-416.

Shammot, M. M. (2011). Factors affecting the Jordanian students' selection decision among private universities. Journal of Business Studies Quarterly, 2(3), 57-63.

Vaidya, O. S., \& Kumar, S. (2006). Analytic hierarchy process: an overview of applications. European Journal of Operational Research, 169(1), 1-29.

Wiese, M., Van, H., Cornelius, H., \& Jordaan, Y. (2010). The role of demographics in students' selection of higher education institutions. Acta Commercii, 10, 150-163. 